\title{
Introduction to the Workshop
}

Penelope Perkins-Veazie ${ }^{1}$

U.S. Department of Agriculture, Agricultural Research Service, South Central Agricultural Research Laboratory, Lane, OK 74555

\begin{abstract}
Organic agriculture has a solid 2\% market share and continues to grow at a rate of $20 \%$ per year. The philosophy of organic agriculture is that application of many pesticides can be avoided by providing conditions for optimum plant health, leading to high quality produce with superior nutritional content. The familiar practices followed in conventional postharvest handling and processing do not always apply to organic produce. Further, the literature is divided about the quality and nutritional merits of organically grown produce. The purpose of this workshop is to provide the guidelines to maintain the certifiable organic label after postharvest handling and processing and to determine systems and component research that scientifically compares postharvest quality, safety, and nutrient content of organic and conventionally grown produce. The four presentations published here provide information on postharvest handling systems and biopesticides that are cleared for organic produce, food safety issues, and nutrient and phytochemical comparisons that can be made with organic and conventionally produced foods.
\end{abstract}

